The csophagus was in a state of gangrene from the comThe trachea downwards, for four fingers' mencement of the the canal was considerably narrowed from chronic inflammation. The thyroid gland was quite destroyed; and communications existed between the pharynx and larynx.

Cagr it Ciroyic Infuamation: Cucer. A female* had for the last ten years of life suffered from difficulty in swallowing, and very frequently during the last two years food was very apt to lodge, and could only be got rid of by retching. In September 1744 she was unable to swallow solids, and soon afterwards had the same difficulty with liquids. The throat seemed paler than usual: she had constant dryness, but no fixed pain, discharge from the mouth, or foctor of breath. For six wecks before her death she was nourished entirely by broth clysters.

The upper part of the oesophagus, for three inches of its length, was converted into a tough brown viscid substance: below this point the canal was narrowed. The thyroid gland was enlarged.

Gase iif. Chronic Iffuamuation: Ulceration below THE Stricture. F., aged $36, \dagger$ within twelve months before her death began to suffer from dysphagia, which gradually increased. She took mercury without bencfit. When seeu, ten months from the commencement of the affection, no solids would pass; thuids passed only with great difficulty and severe pain, which extended to the Fustachian tubes. An attempt was made to pass a bougie, but it was arrested opposite the cricoid cartilage, a smaller one was then tried and passed, but the irritation produced was so great, that it could not be introduced again. Great difficulty was experienced in hawking up the phlegm, and at last this became impossible. For six days before her death, nothing entered the stomach.

Behind the cricoid cartilage a contraction of the canal existed, nearly obliterating it; half an inch below, two spots of ulceration cxisted. 'The thyroid and lymphatic glands were enlarged: this had taken place on the exhibitiou of the mercury.

Case iv Covgenitat Dyspitagia: Cirronic Infla MiMa TION: ULCER BEJOW THE STRICTURE COMMUNICATING WITH THE Lusos. A lady, aged $59, \pm$ had been subject since infancy to a remarkable difficulty in swallowing. For the last thirteen years it had been very troublesome; ind if the food was not well masticated before being swallowed, it became arrested and spasm was produced. Eight months before death, she was seized with pain a little above the pit of the stomach and a sense of chilliness in the back: these seusations left her, but returned at the end of a month, and continued. The food, when swallowed, passed down to the seat of the pain, which seemed to exist close to the orifice of the stomach, The passage of the first morsel was attended with severe agony, but after the second it was less. In addition to the pain, she had constant heartburn, and violent retching; these symptoms increased much in severity during the last six weeks of life, and she spat up a quart of mucus a day, and when the food was arrested, it returned mixed with mucus. A short time before death, an aphthous eruption appeared on the tongue, which spread to the fauces; aud at the same time great difficulty in breathing set in.

The aphtha were found, after death, not to have spread beyond the fauces. The oesophagus was contracted, but not thickened: behind the cricoid cartilage, an inch lower down, a second contraction existed: after this it became larger throughout, but was smaller than common. The canal, for three inches below the bifurcation of the trachea, was in a state of ulceration: from it two sinuses passed into the lungs, but did not communicate with any of the bronchi. The parts surrounding the ulceration were thickened and condensed.

Case v. Chronic Inflammation of the Esophagus: Arscess: Ulcekations com nunicating with the QEsophaGUS A ND LEFT Brovchus. A man, $\S$ who had drank freely of

- Wilmer, Cases and licmarks in Surgery, 1i79.

+ Home, On Stricture of the Urethra and Esophagus.

Ihid.

Merer, Berlin Mod. Zeitung, 1836 spirits, had suffered once from an affection of the stomach, and sereral times from delirium tremens, became, in January 1831 , subject to pain in the chest and stomach. The last wrs relieved by remedies, but the other continued, and was followed by difficulty in swallowing, which increased to such an extent, that solids ceased to descend, and the same difficulty at last extended to fluids. He lost much flesh and strength. In July and August he suffered severely from hunger and thirst; his skin was hot; and fluids had ceased to enter the stomach. An attempt was made to pass a small tube, but without effect. On the lst of September, he began to suffer from cough with purulent expectoration: and on swallowing fluids, they remained scme time at the point where the obstruction existed; cough then came on, and they were rejected. This state continued up to time of death on the 24 th. He was nourished by clysters.

From the middle of the œsophagus, as low as the orifice of the stomach, hard gristly thickening existed; and it was so narrowed, that the smallest catheter would not pass. Opposite the lower part of the trachea, a large mass of cellular tissue existed, which was in close connexion with the parts adjo the sac of an abscess. Communications existed between it and the osophagus and the left bronchus.

Case vi. Chronic Implammation: Ulcebation. M. aged 42, received, six months previously, a kick from a horse in the epigastric region, by which severe pain was excited. He soon after had an attack of ague. Difficult and painful deglutition set in after a cold, attended with burning sensation in the upper part of the epigastrium, and tenderness on pressure. No vomitirg or nausca aftcr eating. existed, nor cough or difficulty in breathing. The appetite was good, and the bowels natural. A laxative on the 5th of June produced much relief. On the 7 th, the difficulty in deglutition became much worse, and on the 11 th, a dry cough set in with constriction of the throat, fotid odour from the mouth, and heartburn. The obstruction seemed to exist at two points, near the larynx and at the orifice of the stomach. On the 15 th, the cough was worse, much viscid mucus being brought up. By the 22 nd, the strength was much reduced: and foctid pus was coughed up. He sank one month from. this time. The obstruction at the upper part of the canal disappeared a fortnight before death.

The osophagus opposite the fifth dorsal vertebra was so. narrowed for an inch of its length, that a pen with difficulty could be made to pass; above this the canal was enlarged, and. contained purulent ichorous tluid. The whole of this tract was of a livid grey hue and adherent to the trachea: the two canals seemed to have a common oritice. The lungs were not adherent, but they were filled with spumous serum and blood. No tluid was found in the pleural cavities.

Harritugton Square, London, Sept. 1853.

\section{ON DEGENERATIONS OF THE GLANDULAR STRUCTURE OF THE STOMACH.}

By C. HANDFIELD JONES, M.B.Cantab., F.R.S., Assistant Physician to St. Mary's Hospital.

Ir is an ungrateful task for the pathological observer to have to add to the number of morbid changes, which, there is but too much reason to fear, are irremediable. From this unwelcome knowledge, however, one advantage, at lcast, results: that the mind of the practitioner is saved from that painful feeling of disappointment which naturally follows when we find remedies of no avail in cases where we trusted they might have been potent for good. It is at least some satisfaction, though a poor one, to know that our best directed efforts to restore healthy action may fail, not because our measures were inappropriate to the case, but because the structure whose function we would restore had perished. Probably there is no organ in the body on whose

- Yauchart, de Struma Ficophagi, in Haller's Dirp. Chir. Selecta, lib. if. 
healthy condition so much of our comfort depends as the stomach, none, in consequence, whose silments have been more studied and written upon; and yet it seems rather remarkable that hitherto we have had no careful investigation of the morbid changes which its mucous membrane (that most essential part of it) undergoes. No one has yet done for the stomach what Johnson, Simon, and Frerichs, not to mention others, have done for the kidney. And yet the mucous membrane of the stomach is a true gland structure, essentially different from that of the intestine; its follicles are not mere involucra of the surface, they possess a much higher function than that of merely secreting mucus. Examination of a vertical section of the healthy tissue shows that in the greater part of its extent it is made up of parallel tubes ranged side by side, and so close together that there are scarcely any interspaces discernible. These tubes are nearly of the same size as, and altogether very similar to, those of the kidney; the chief difference is, that they are more filled with epithelium, and do not exhibit a distinct central canal. They terminate as they reach the corium of the mucous membrane by blind extremities, which are often slightly bulged, and sometimes slightly branching. Above, they open into shallow fossule, which we well represented in Bowman and Todd's Physiology, vol. ii, p. 193. These fossulae are lined by an epithelium consisting of columnar particles, while that which fills the tubes consists of nuclei imbedded in granulous matter, and very numerous large nucleated cells full of granulous conterits. This gastric glandular epithelium differs from the renal in this important circumstance relative to the discharge of its function, that it does not remain, like the latter, attached to the basement membrane, the wall of the tube, but is thrown off and constitutes itself a part of the secretion. In the pyloric region, the fossulæ are very much deeper, and the entering tubes much shorter; while low villi, containing single capillary loops, spring from the partition walls of the fossula. In the other regions of the stomach there are no true villi, but a deceptive appearance is occasionally presented by papilloid masses of altered epithelium exuding from the tubes.

One morbid condition which is not uncommonly olserved, is an atrophic state of the lower ends of the tubes and of their epithelium. The latter, then, consists of coarse granular matter, with a few stunted, starved-looking nuclei and cells which often contain oily molecules. The lower blind ends of the tubes are faintly marked, and sometimes are evidently tending to disintegrate; at the same time the interspaces betwee:a adjacent tubes seem wider, as if some had already disappeared. In some cusses the epithelium is altered, containing no healthy cells, but filling up the tubes with a coarse granular matter, while they themselves are not atrophied.

A fatty change in the epithelium is not uncommon, and in some degree is scarcely to be regarded as of pathological import. The lower ends of the tubes in our domestic animals are often quite opaque from the presence of much oil in the epithelium : there is, however, in such instances, no indication of wasting or breaking up of the tubes. Sometimes the glandular tissue seems to undergo what may be called true fatty degeneration: the tubes lose much of their natural aspect, and become converted into cylindrical tracts of granular matter loaded with oil drops. When the epithelium is in a fatty state, the inner surface of the stomach will often be found to be of a dead dull white colour; and it is rather remarkable that sometimes the change is confined to patches of varying extent, perfectly circumscribed. This change in the colour of the stomach is noticed by Andral as the result of chronic gastritis.

Together with a varying degree of atrophic change in the tubes themselves, there is often observed a remarkable alteration of the submucous tissue, or rather of the areolar tissue which forms a kind of corium to the mucous membrane. On viewing a vertical section, masses of nuclear particles are seen heaped up among the fibres, where they come in contact with the blind ends of the glandular tubes; these increase and advance upwards between the tubes, and occasion or coincide with their atrophy. The masses of nuclei are separate from each other, a certain space of healthy tissue intervening between them. The spots occupied by the nuclear deposits are sometimes depressed, so as to give rise to an appearance of open follicles. In an extreme instance the nuclear deposit has so increased as to cause almost a complete atrophy of the tubes, debris alone of which can then be discerned amid the altered intervening tissue. Vascular injection is by no means a constant accompaniment of this condition; and when it exists, it has not appeared to me at all clear that it was not of a passive kind. Together with the nuclei there is a certain quantity of granulous matter, which varies, however, in amount : it is not generally enough to conceal the nuclei.

Sometimes the exudation shows some tendency to the production of fibroid tissue, but I have never seen this developed in a very marked manner. Perhaps, however, contraction of the surrounding arcolar tissue may have been the cause of the peculiar alteration observed in the following instance.

In a female, of thin and spare habit, who had been ailing two years, and who died of bronchitis with emphysema and dilatation of the heart; the liver was in a highly nutmeg state, and its Glissonian sheaths were considerably thickened; the kidneys were not healthy, and they contained reddish yellow pigment, the sign of former extravasations of blood. The mucous membrane of the stomach in the region adjoining the pylorus had a mammillated aspect, and was of a reddish brown colour. It was covered over with small, indistinct, sometimes whitish eminences, which were very apparent on a vertical section as whitish grain-like masses in the deeper parts of the mucous membrane. These masses consisted of tortuous tubes crowded and packed together, and filled with an epithelium consisting of small sized cell particles containing oily molecules, and of free nuclei imbedded in abundant granular matter. The basement tissue of the tubes was distinct in the masses, but could not be traced upwards to the mucous surface. In fact, the convoluted tubes seemed quite destitute of any outlet for their contents. The masscs were separate from each other, and were closely girt by layers of fibroid tissue which seemed to compress them. In their intervals there was no trace of tubes. The epithelium of the surface preserved its usual columnar form.

I subjoin further details of the examination of some instances of the degenerative changes in the gastric mucous membrane above described.

A pallid, ill nourished female, aged 22 , who had long suffered with epigastric uneasiness and bad digestion, died of phthisis and bronchitis. She had been fifty-one days in the hospital, and had undergone the operation for ruptured perinæum, which proved quite successful. The contents of the stomach were acid. Some portions of the mucous lining were of a dead white, and presented the appearance of numerous quasi-follicular orifices; the rest was of a faint reddish grey tint. There was no vascular injection anywhere. The white parts of the mucous membrane showed on a vertical section parallel rows of tubes filled especially at their deeper parts with oil laden cells of very perfect form and great consistence; these cells contained oil dots, opaque and black (but not drops), imbedded in much granulous matter. Besides the cells, the contents of the tubes consisted of free nuclei and granulous matter. The tubes were not broken up; but every here and there the row was interrupted, and there was left an empty looking space, which was occupied either by remains of tubes atrophied and containing merely a faint granulous matter, or by a mass of nuclei only. In one section the tubes existed only at the upper half or two-thirds of the vertical extent of the mucous membrane, while at the lower they were atrophied and replaced by a mass of nuclei. It was these interruptions in the continuity of the tubes which gave the appearance of follicular orifices. In the pale non-whity portions of the mucous membrane the epithelium was much less fatty.

A man, aged 63, died with empyema, the consequence of an accident which had fractured several ribs. The cornea 
presented distinct arcus seniles. There was but slight fatty change of the muscular fibres of the left ventricle. The kidneys were not quite healthy; there were cysts on their surface. The inner surface of the stomach was of a pale colour, rather uneven; the mucous membrane to the eye was not much altered, but under the microscope the tubes were found to be extremely wasted, and in many parts quite lost, and replaced by a granular and fibrous tissue containing multitudes of ill shaped nuclear particles. In some parts there were groups of convolutions and bulgings of the tubes, stuffed with an opaque granulous and oily matter. The atrophy of the tubes was extremely marked. There was fibrinous deposit in the spleen.

A female, aged 19, died with syphilitic phagredena of the genitals. The stomach presented a natural aspect, with the exception of some slightly raised spots of the size of a pin's head in the vicinity of the pylorus. These seemed to be produced by accumulations of epithelium in the fossulæ. The tubes in this part were in a normal state. In the midregion of the stomach the tubes were much wasted, those remaining only contained a granulous and oily matter.

In a middle-aged female, dying with scirrhus pylori, the stomach was found distended to some extent; its muscular coat was much hypertrophied; its mucous membrane apparently healthy. On closer examination, the lower ends of the tubes near the pylorus were seen to be aggregated into bunches, while in other parts they were very indistinct, evidently atrophied, and surrounded by intertubular exudation, consisting of nuclei and granulous matter. In one section, two large cysts were seen, full of a transparent fluid, and lined by a delicate vesicular epithelium. They lay in the substance of the mucous menbrane. The kidneys were granular and cysted. There was considerable fibroid thickening of the capsule of the spleen. and some also of that of the liver.

A man, aged 51 , addicted to drinking, and subject to gout, died with double pneumonia, pleurisy, and pericarditis, after five days' illuess. 'The kidneys were healthy. The stomach appeared markedly mammillated in its midregion; it was not injected. The tubes appeared pretty natural, but were obscured by an interstitial exudation, developing itself into nuclei and granulous or perhaps indistinct fibroid matter: at one part there was a large nodular accumulation, consisting solely of nuclei. From this mass, the nuclear deposit extended in smaller quantity among the tubes, and would, at a later period, have no doubt occasioned their atrophy. The mucous membrane of the fundus was red and softened; but its tubes were quite natural, and unobscured by any intervening exudation. The pyloric portion, like the cardiac, showed no trace of mammillation: there was, however, in this part very considerable intertul,ular fibroid formation, with infarction of the lower ends of the tubes by oily and granular matter; and gathering up of their lower parts into bunches. Many tubes in this part were also atrophied, so that a section no longer presented a continuous row.

In a female, aged 43 , who died of uterine cancer. he mucous surface of the stomach was of a dead whity colour throughout. The tubes were not wasted, but werefilled with a very opaque fatty epithelium. In the mid-region, towards the greater curvature, there was a marked mammillated aspect; this very nearly disippeared after dissecting the mucous membrane from the submucous, and spreading it out. It was probahly caused by some irregular contraction. The liver was excessively fiutty.

A female, aged 87 , died with universal jaundice; the femur was fractured by a fall some days before death. The liver was somewhat granular on the surface, and the Glissonian sheaths appeared somewhat thickened. The ductus communis choledochus was obstructed at its lower part by a soft mass of biliary pigment matter; the gall-bladder was hence enormously distended. The kidneys were wasted and granular. The stomach was very large; the mucous membrane was quite pale, but not manifestly unhealthy to the eye. Under the microscope, it was seen to be gravely altered; there was very little trace of tubes to be discovered even on repeated examinations; here and there were some traces of them, but in by far the greater part of the tissue they had perished. Their place was occupied by a quantity of nuclear particles, granulous and some oily matter, and occar sionally fat resicles. The formation of nuclear particles had extended quite into the corium of the mucous membrane.

A man, aged 37, died with general peritonitis, after the recto-vesical operation, undertaken in consequence of the urethra being obliterated by stricture. The stomach appeared natural to the eye. In the middle and the splenic regions, the epithelium of the tubes consisted of small, stunted, atrophied particles, appearing more like empiy vesicles than anything else ; it was not fatty. In the pyloric third, the epithelium was not atrophied; large granular round and oval cells were present in the exuding contents of the tubes, besides free nuclei and granulous matter.

A stout man, aged 52 , man, in apparent health, died with extravasation of blood within the cranium, after a blow. The mucous lining of the stomach had a dead white appearance, and seemed to be irregularly mammillated, or as if its surface was every here and there somewhat elevated. The epithelium of the tube was much atrophied; it consisted of stunted cells, granular matter, and ill developed nuclei. The tubes themselves were wasted in some degree; their deep ends were most affected, and lay imbedded in a stratum of granular matter, containing numerous nuclear particles, which infiltrated the areolar tissue. Acetic acid brought the intertubular nuclei more plainly into view.

I do not intend on this occasion to enter into any detailed examination of the causes and nature of the above changes; I can only state that I am not inclined to regard them as of inflummatory origin. They seem to us to belong much niore nearly to the class of pure and simple degenerations, occurring as primary morbid phenomena, from the decay of vital power. Hyperamia has not appeared to form any constant or necessary element of these textural changes. In the case of the nuclear formations, it is clear that there is intertubular exudation; but we have no evidence to show that it is the product of inflammatory action; I should rather consider that, owing to derangement of the natural assimilative power, the plasma, which should have formed healthy epithelium and other structures, was developed into these abnormal organizations. The morbid action seems to acknowledge a relation to cirrhosis of the liver, and to changes of the like kind. 'The newly formed fibroid tissue in cirrhosis is often loaded with nuclei, quite similar to those produced in the gastric masses. It is of course a matter of great difficulty to study satisfactorily the genesis of these morbid states; for, although there is strong ground for supposing that they exist in many of the multitudinous valetudiuarians who are the commonest subjects of medical treatment; yet, as such individuals live on for years, and often die of some acute malady, there is seldom an opportunity of examining the organ affected while the change is in progress. To this subject I hope to devote much attention in future years, and shall be very thankful to any confrère who will furnish specimens and brief histories of the symptoms existing during life.

'Ihe practical results which the above investigation, as far as it has extended, supplies are:-1. That we may expect not unfrequently to meet with cases where the digestive power of the stomach is permanently weakened by the decay of more or less of its glandular structure. 2. That, in a still greater number of cases, the digestive power is weakened from an atrophy of the epithelium, which, it is conceivable, may, by judicious administration of light nourishing food, cod-liver oil, and gentle tonics, be reproduced in a more healthy state. 3. That we must be cautious in leeching or blistering epigastria for the removal of gastritis, which may have no existence. The further our observation extends, the more do we become convinced that the most hopeless diseases with which we have to contend are those depending on essentially chronic degene- 
rations of organs. Who would not rather have to deal with an acute pneumonis or pericarditis, than with a case of confirmed morbus Brightii? How often does our healing skill hang its head in hopeless foreboding when our diagnosis has revealed the existence of an organic lesion! This must of course often be; but how needful then does it become that we should be thoroughly aware of these degenerative tendencies, and exercise the utmost vigilance to anticipate and stay those destructive changes which we are unable to reverse.

1, Southwick Place, Hyde Park, London, Sep. 22nd, 1853.

BRAIN AND HEART DISEASE, WITH FXTRAORDINARY AND LONG CONTINUED REDUCTION IN THE FREQUENCY OF THE PULSE.

By ALEXANDER HENRY PATELSON, Esq.

CASE. T. S., aged 62, a merchant in Glasgow, came under my care on Sept. 25th, 1852. He was a short, very stout, and apparently healthy man, with a quick intelligent face and an energetic manner. In his previous habits he had been very active; he had travelled much for many years, and was very temperate. His previous health had been good, except that he had had frequent attacks of chronic bronchitis since the age of 18 , and had within the last three years had three attacks of giddiness, caused by strong mental excitement, and producing momentary insensibility. On these occasions be fell to the ground, but immediately recovered himself, and had not either before or afterwards any headache, paralysis, or other symptom of brain disease.

In April 1852, Mr. S. was for the greater part of the day engaged in looking over a farm a few miles from home: and on his return, he endeavoured to overtake an omnibus. For this purpose he ran up a hill; and, having taken his seat, suffered much from difficulty of breathing and palpitation. These symptoms increased, and a few hours after his return home he was seen by a physician, and found to be dangerously ill, with congestion of the lungs and bronchitis. For many days he was unable to lie down; the pulse, which in health had been about sixty, now beat twenty-six times in the minute. Anasarca rapidly showed itself in the legs and thighs. The kidneys acted very imperfectly. The brain, and nervous system generally were unaffected.

The treatment was diuretic and expectorant; and at the end of a month the more urgent symptoms abated. The lungs continued very generally congested; the cough was troublesome, the expectoration copious, and the anasarca diminished. Mr. S. breathed easily when the shoulders were well supported, but could not lie flat down, and suffered very much from shortness of breath on making the least exertion, particularly in attempting to walk up stairs.

Mr. S. continued gradually to improve till September, when he was advised to winter in a milder climate; and for that purpose he came to Bowdon. His general appearance I have described. He at this time had no blueness of lips, or other indications of venous congestion. His extremities were cold unless well clothed; he could take excrcise with pleasure on a perfectly level surface, but on attempting to walk up a slight ascent or a few stairs, his breathing became painfully hurried, and he said that he lost all power. The tongue was clean and healthy; the skin pale, otherwise normal; the appetite was tolerable, but he suffered much from flatulence. The kidneys actod froely. Theme was slight pitting at the ankles; the bowels were rather slusgish. $\mathrm{He}$ had had for some years a setom in the neck for the attacks of giddiness, and had for the last two manths also had one in the left side. The pulee was 28 , sill, and psetty strong. Mr. S. suffered from no pain, and chiefly complained of disturbed nights. He had his shoulders supported by two or three pillows, but was apt to slip from them, and was then disturbed by difficulty of breathing and increased cough. He was also, frequently, when free from this, unable to sleep on account of restleseness. The pulse had been as high as 32, but had not exceeded this since $A$ pril.

A careful examination failed to detect any symptoms of cerebral or spinal disease. The lungs appeared generally dull, and mucous ralles were heard all over them, particularly posteriorly. There was frequent cough, with very free expectoration of frothy mucus. The heart beat with increased impulse, but the stroke was undecided and the sounds confused and indistinct. The impression giren by the physical signs was that there existed either pericardial effusion, or absence of the mitral valve; but the extreme stoutness of the patient and the ralles in the chest obscured the diagnosis. Mr. S. had for some months been taking sarsaparilla with acetate of potash, and pilula ferri cum assafœetidà; as well as some mild aperients. This plan of treatment was continued by me, with some occasional varistions of the diuretics.

In the course of a few weeks, Mr. S. very decidedly improved. His pulse rose to 32 . His cough was much relieved, and he could walk slowly up stairs without pain or mucb distress. The chief annoyance was from flatulence and restless nights. The diet was most carefully regulated, and medicine was nearly left off. On October 16, I was hastily sent for, and found Mr. S. apparently dying. The surface was cold; the face of a lead colour; the veins of the neck were very turgid; the breathing was stertorous; there was partial insensibility, and a feeble pulse of 28 .

Mr. S., having on the previous day dincd on Irish stew, had gone to bed in his usual health. Early in the morning, feeling some nausea, he rose for the purpose of taking a Seidlitz powder, and fell back in the state I have described. He shortly afterwards romited; and, after taking some brandy and chloric ether, he gradually recovered his usual state.

My patient now had again an interval of tolerable health; he could walk two or three miles, wrote, read, and talked well, and for an hour or two at a time; and with increased care in his diet, he avoided a recurrence of such attacks.

In January 1853, Mr. S. had a few friends to dinner, and appeared in tolerable health. In the course of the evening, he went for a purpose of nature into the yard. While he was there, a servant quickly opened a back door. Being startled, he sprung a few steps backwards, and fell fainting to the ground. He was with difticulty carried to a sofa, and slowly recovered. About this time he complained of wandering pains in the head; and I thought his memory rather affected. After consulting his former medical attendant, we agreed to apply a blister to the nape of the neck, and give two grains of blue pill twice a day till the gums were slightly affected. The medicine was taken for nearly three weeks; it then produced the desired effect, and appeared to have caused some intermittence in the pulse. It was given up, and I did not again detect any head symptoms.

About the 12th of March, Mr. S. pointed out a pimple between his shoulders with a hardened base. This quickly enlarged, and became a carbuncle of the size of a cheese plate. The treatment consisted in occasional small doses of opium, wine and good diet, and stimulating poultices. I did not venture to make a free incision, fearing a dangerous return of the fainting and collapse. This carbuncle was followed by two more, smaller in size, but still giving extreme pain, and causing wuch thirst and restlessness. The pulse at this time varied; being on April 17th, at 10 A.M. 36 , and at 5 P.M. 46. It was intermittent, particularly when sitting up in bed, and bofore taking food. I ventured on May lst to lance the last carbuncle freely; and my patient bore the operation very well. He now began to recover his strength, his appetite being good. On the 4th of May, he got down stairs, and noticed his legs pitting, but there was no fluid above the knees. His urine was examined, and found to be natural in quantity and quality. His pulse was strouger (about 30), with occasional intermissions. On 23rd May he left Bowdon, and shortly afterwards returned to Scotland.

From Dr. Bell, of Glasgow, I haye received the following account of the conclusion of this extraordinary case: 